\title{
Implementing anti-retroviral triple therapy to prevent HIV mother-to-child transmission: a public health approach in resource-limited settings
}

\author{
Cristina M. Marazzi • Paola Germano • \\ Giuseppe Liotta • Giovanni Guidotti • \\ Sandra Loureiro • Aurelio da Cruz Gomes • \\ Maria C. Valls Blazquez • Pasquale Narciso • \\ Carlo F. Perno • Sandro Mancinelli • \\ Annamaria Doro Altan • Karin Nielsen-Saines • \\ Leonardo Palombi
}

Received: 13 October 2006 / Accepted: 18 December 2006 / Published online: 18 January 2007

(C) Springer-Verlag 2007

Keywords HIV MTCT · Anti-retroviral therapy Public health $\cdot$ Resource-limited settings

We conducted a retrospective cohort study of HIV-infected pregnant women and their infants enrolled in the DREAM programme for prevention of HIV mother-to-child transmission (MTCT) in Mozambique. All women delivering between May 2002 and December 2005 were offered participation. The programme consisted of the provision of highly active anti-retroviral therapy (HAART) to pregnant women until 6 months postpartum, and formula, clean water, nutritional supplementation, and continuing HAART to mothers if necessary.

All authors are also affiliated with the DREAM Programme (Drug Resources Enhancement against AIDS and Malnutrition).

C. M. Marazzi

LUMSA University,

Rome, Italy

P. Germano

Community of Sant'Egidio-DREAM programme,

Rome, Italy

G. Liotta C. F. Perno $\cdot$ S. Mancinelli $\cdot$ A. D. Altan $\cdot$ L. Palombi

University of Tor Vergata,

Rome, Italy

G. Guidotti

National Institute of Health,

Rome, Italy
In Mozambique 1,259 HIV-positive pregnant women were offered participation: 212 (14.4\%; CL95\% 12.6-16.2) refused, 54 (3.7\%; CL95\% 2.5-4.9) dropped out during pregnancy, and eight women died. The remaining 985 women participated, giving birth to 958 infants, including 21 sets of twins. An additional 28 babies were stillborn. Spontaneous abortions occurred in 20 cases. Discontinuation of anti-retroviral (ARV) therapy by mothers was $3.7 \%$ $(54 / 1,464)$ before delivery, $1.5 \%$ in the first month $(23 /$ $1,464)$, and $1.5 \%(22 / 1,464)$ between the first and sixth months after delivery. Overall drop-out rates were 5.2\% (CL95\% 4.6-5.8). Approximately $80 \%$ of pregnant women completed the treatment protocol.

S. Loureiro · M. C. V. Blazquez

DREAM Programme,

Maputo, Mozambique

A. d. Gomes

Catholic University of Beira,

Beira, Mozambique

P. Narciso

National Institute of Infectious Disease "L. Spallanzani”,

Rome, Italy

K. Nielsen-Saines $(\square)$

Department of Pediatrics,

David Geffen UCLA School of Medicine,

MDCC 22-442 10833 LeConte,

Los Angeles, CA, USA

e-mail: knielsen@mednet.ucla.edu 
Table 1 Base-line parameters (993 pregnancies)

\begin{tabular}{lll}
\hline Parameter & Median & IQ 25-75 \\
\hline Age (years) & 24.3 & $21.2-28.6$ \\
Start of ARV therapy (week of pregnancy) & 26.8 & $25.1-31.0$ \\
Pre-ARV therapy CD4 count & 489 & $312-692$ \\
Pre-ARV therapy viral load ${ }_{\text {log }}$ & 4.17 & $3.65-4.55$ \\
Pre-ARV therapy Hb & 10.1 & $8.7-10.6$ \\
Length of pregnancy (weeks) & 38.5 & $36.1-40.2$ \\
Pre-delivery days of ARV therapy & 72 & $36-98$ \\
\hline
\end{tabular}

Anti-retroviral treatment induced a significant reduction in virus load, with the percentage of women with fewer than 1,000 viral copies per millilitre $(\mathrm{c} / \mathrm{ml})$ rising from $17 \%$ at baseline to $90 \%$ by the time of delivery. A total of 707 children were tested at 1 month of age, and 467 were retested at 6 months. The HIV incidence rate was 3.8\% (CL95\% 3.1-4.5) at 1 month, with an additional 1.5\% (CL95\%: 0.9-2.1) of babies testing positive at 6 months. The cumulative intention-to-treat incidence rate was 5.3\% at 6 months. When data for women who stayed on treatment for the full duration of the protocol were analysed separately, vertical transmission rates dropped to $1.4 \%$ at 6 months. Maternal mortality was $0.8 \%$ (eight deaths in 993 pregnancies). The incidence rate of significant hepatic, dermatological and haematological adverse reactions to anti-retroviral agents on a sub-sample of 778 pregnant women was 6.1\% (CL95\% 4.2-8.0), 3.2\% (CL95\% 2.03.4 ) and $14.1 \%$ (CL95\% 11.6-16.6), respectively.

Base-line parameters, risk factors for vertical transmission, and multivariate analysis of the determinants of HIV positive status are shown in Tables 1, 2 and 3.

The current data are highly relevant for the development of future programmes for the prevention of HIV MTCT in the developing world. The acceptability of HAART during pregnancy was higher than that of single-dose nevirapine in prior studies [5, 6]. Even within the Mozambique health care system, where about $50 \%$ of women deliver at home, it was still possible to get women tested for HIV early in the course of pregnancy. A surprisingly large percentage of women (86\%) who tested positive enrolled, and 95\% (931/ 985) of those completed the entire protocol. The public health impact on vertical transmission was much higher than previously described [1, 3-6], with a cumulative intention-to-treat (ITT) analysis transmission rate at 6 months of age of $5.3 \%$. Among women who received HAART until 6 months postpartum, no transmissions occurred beyond 1 month of age. These results demonstrate that, in resource-limited settings, very low HIV transmission rates, equivalent to those observed in developed countries, are achievable [2]. In addition, the decision to use HAART in the postpartum period could potentially render breastfeeding safe during the first 6 months of life.

Table 2 Risk factors for vertical transmission and multivariate analysis of HIV positive status determinants (HIV status assessed 1 month after delivery-forward stepwise logistic regression analysis). $N V P$ nevirapine

\begin{tabular}{|c|c|c|c|c|c|c|}
\hline \multicolumn{2}{|l|}{ Parameter } & \multirow{2}{*}{$\frac{\text { Number }}{343}$} & \multirow{2}{*}{$\frac{\mathrm{HIV}+}{4}$} & \multirow{2}{*}{$\begin{array}{l}\text { Percentage } \\
1.2\end{array}$} & \multirow{2}{*}{$\begin{array}{l}\text { Odds ratio } \\
5.6\end{array}$} & \multirow{2}{*}{$\frac{95 \% \mathrm{CI}}{1.9-16.4}$} \\
\hline Viral load (c/ml) & $<10,000$ & & & & & \\
\hline & $>10.000$ & 337 & 22 & 6.1 & & \\
\hline \multirow{2}{*}{$\begin{array}{l}\text { Pre-ARV therapy haemoglobin } \\
(\mathrm{mg} / 100 \mathrm{ml})\end{array}$} & $>7$ & 644 & 21 & 3.2 & 4.1 & $1.5-11.6$ \\
\hline & $<7$ & 37 & 5 & 11.9 & & \\
\hline \multirow[t]{2}{*}{ NVP to the baby } & No & 126 & 4 & 3.1 & 1.2 & $0.4-3.7$ \\
\hline & Yes & 555 & 22 & 3.8 & & \\
\hline \multirow[t]{2}{*}{ Pre-delivery length of ARV therapy } & $<80$ & 368 & 20 & 1.5 & 3.0 & $1.2-8.1$ \\
\hline & $>80$ & 280 & 5 & 5.2 & & \\
\hline \multirow[t]{2}{*}{ Place of delivery } & Reference centre & 386 & 13 & 3.3 & 1.3 & $0.6-2.9$ \\
\hline & Others & 295 & 13 & 4.2 & & \\
\hline
\end{tabular}

Table 3 Logistic regression analysis - independent predictors of HIV MTCT

\begin{tabular}{llllll}
\hline Parameter & B & E.S. & Sig. & Exp(B) & 95\% CI per Exp (B) \\
\hline Viral load (c/ml) & 1.605 & 0.556 & 0.004 & 4.979 & 1.766 \\
Pre-ARV therapy haemoglobin & 1.164 & 0.544 & 0.032 & 3.204 & 1.103 \\
Pre-delivery length of ARV & 1.107 & 0.512 & 0.030 & 3.026 & 1.110 \\
\hline
\end{tabular}




\section{References}

1. Ayouba A, Tene G, Cunin P, Foupouapouognigni Y, Menu E, Kfutwah A, Thonnon J, Scarlatti G, Monny-Lobe M, Eteki N, Kouanfack C, Tardy M, Leke R, Nkam M, Nlend AE, BarreSinoussi F, Martin PM, Nerrienet E; Yaounde European Network for the Study of In Utero Transmission of HIV-1 (2003) Low rate of mother-to-child transmission of HIV-1 after nevirapine intervention in a pilot public health program in Yaounde, Cameroon. J Acquir Immune Defic Syndr 34(3):274-280

2. Dorenbaum A, Cunningham $\mathrm{CK}$, Gelber RD, Culnane $\mathrm{M}$, Mofenson L, Britto P, Rekacewicz C, Newell ML, Delfraissy JF, Cunningham-Schrader B, Mirochnick M, Sullivan JL; International PACTG 316 Team (2002) Two-dose intrapartum/newborn nevirapine and standard antiretroviral therapy to reduce perinatal HIV-1 transmission: a randomized trial. JAMA 288(2):189-198

3. Guay LA, Musoke P, Fleming T, Bagenda D, Allen M, Nakabiito C, Sherman J, Bakaki P, Ducar C, Deseyve M, Emel L, Mirochnick
M, Fowler MG, Mofenson L, Miotti P, Dransfield K, Bray D, Mmiro F, Jackson JB (1999) Intrapartum and neonatal single-dose nevirapine compared with zidovudine for prevention of mother-tochild transmission of HIV-1 in Kampala, Uganda: HIVNET 012 randomised trial. Lancet 354(9181):795-802

4. Songok EM, Fujiyama Y, Tukei PM, Vulule JM, Kiptoo MK, Adungo NO, Kakimoto K, Kobayashi N, Genga IO, Mpoke S, Ichimura H (2003) The use of short-course zidovudine to prevent perinatal transmission of human immunodeficiency virus in rural Kenya. Am J Trop Med Hyg 69(1):8-13

5. Stringer EM, Sinkala M, Stringer JS, Mzyece E, Makuka I, Goldenberg RL, Kwape P, Chilufya M, Vermund SH (2003) Prevention of mother-to-child transmission of HIV in Africa: successes and challenges in scaling-up a nevirapine-based program in Lusaka, Zambia. AIDS 17(9):1377-1382

6. Stringer JS, Sinkala M, Goldenberg RL, Kumwenda R, Acosta EP, Aldrovandi GM, Stout JP, Vermund SH (2004) Universal nevirapine upon presentation in labor to prevent mother-to-child HIV transmission in high prevalence settings. AIDS 18(6):939-943 